\title{
Sobre uma carta de Machado de Assis a José Feliciano de Castilho (1865)
}

\section{A letter from Machado de Assis to José Feliciano de Castilho (1865)}

Ana Carolina Sá Teles ${ }^{1}$

Doutoranda na Faculdade de Filosofia, Letras e Ciências Humanas (FFLCH-USP) com o Projeto Personagens machadianas em Ressurreição, Helena e Dom Casmurro" na area de Literatura Brasileira, sob orientação do Prof. Dr. Hélio de Seixas Guimarães, desde 2014. Na mesma "Questzono, realizou Mestrado, com o Projeto "Qu contos de Machado de Assis" (20102013) que contou com o financiamento da FAPESP. Recentemente publicou artigo "Aprendizagem da dissimulação no conto machadiano 'Ponto de vista (Quem desdenha)'" na Revista Machado de Assis em Linha, v. 7, 2014.

anacarolinateles2009@gmail.com
RESUMO: As cartas de Machado de Assis ganharam nova forma de circulação, a partir de 2008, com a edição coordenada por Sérgio Paulo Rouanet e reunida por Irene Moutinho e Sílvia Eleutério. Este artigo volta-se para a correspondência machadiana da década de 1860 e analisa uma carta pública que Machado de Assis escreveu para José Feliciano de Castilho em 1865. Nela, Machado analisa a comédia de José Mendes Leal, Os primeiros amores de Bocage (1865). Assim, observamos um testemunho da crítica literária produzida pelo autor brasileiro no gênero epistolar. Nota-se que essa carta machadiana tem uma função que vai além do convencionalismo, demonstrando atuação crítica. Além disso, o jovem Machado de Assis articula o texto com a finalidade estabelecer relações de sociabilidade e filiação a determinada tradição literária.

Palavras-chave: Machado de Assis; José Feliciano de Castilho; José Mendes Leal; Correspondência

ABSTRACT: Machado de Assis' letters have been read in a new way since an edition published in 2008, which was coordinated by Sérgio Paulo Rouanet, and compiled by Irene Moutinho and Sílvia Eleutério. This article approaches Machado de Assis' correspondence in the 1860's, and analyses an open letter that the author wrote to José Feliciano de Castilho in 1865. In this letter, Machado analyses José Mendes Leal's comedy Os primeiros amores de Bocage (1865). Thus, the text presents a testimony of criticism written in the epistolographic genre by the Brazilian author. It is possible to note that this letter goes beyond conventionalism, as it shows critical engagement. Furthermore, it allows us to observe a young Machado de Assis that writes the text in order to establish social relationships, as well as to relate to a certain literary tradition.

KEYworDS: Machado de Assis; José Feliciano de Castilho; José Mendes Leal; Correspondence 
$\mathrm{N}$ este artigo, analiso a carta escrita por Machado de Assis em 15 de agosto de 1865, dirigida ao escritor português José Feliciano de Castilho. A carta de Machado tem como assunto central a comédia Os primeiros amores de Bocage, escrita pelo autor também português José Mendes Leal, publicada naquele mesmo ano.

Na Correspondência de Machado de Assis, lemos a seguinte descrição sobre o correspondente José Feliciano de Castilho:

Em 1847, emigrou para o Brasil, onde fundou o jornal Íris, publicando alguns livros antigos, como o Diálogo das Grandezas do Brasil. Em 1862, Machado de Assis fez restrições aos seus livros À memória de Pedro IV e Memória sobre a $22^{a}$ Égloga de Virgílio. Tornaram-se amigos em 1865, na fundação da Arcádia Fluminense, durante as comemorações do centenário de Bocage (1765-1865), de quem Castilho José foi biógrafo. Nada mais natural, portanto, que a ele Machado de Assis tenha se dirigido em carta aberta transcrita no Diário do Rio de Janeiro em 15 de agosto de 1865, recomendando-lhe a peça Os primeiros amores de Bocage, de Gomes [sic] Leal. (ASSIS, 2008, p. 294)

Tanto por se dedicar quase exclusivamente ao assunto da peça, quanto por ocupar o espaço impresso de uma carta aberta, esse texto de 1865 constitui uma nota crítica de Machado de Assis. Portanto, para a análise detalhada da carta, é necessário estabelecer referências a duas obras. Ou seja, é relevante abordar a peça de José Mendes Leal, Os primeiros amores de Bocage, que é objeto da crítica. Em adição, é relevante revisitar a biografia que José Feliciano de Castilho escreveu sobre Bocage.

Pretende-se aqui analisar as categorias literárias a que Machado de Assis refere-se na carta, como, por exemplo: os gêneros da peça, a comédia de enredo, de caracteres e de costumes; a figuração de personagens; além de questões sobre representação literária.

Tem-se em vista, ademais, relacionar os problemas levantados pela crítica de Machado de Assis não apenas ao interlocutor, Castilho José, e à obra de Mendes Leal, mas também a questões relevantes no projeto estético do próprio escritor brasileiro. Assim, a partir do comentário de Machado de Assis sobre essa comédia, encontramos questões referentes aos caracteres e à representação literária que são importantes em diversos momentos de sua obra ficcional e crítica.

Em “Epistolografia de Machado de Assis: escrita de si e testemunhos de criação literária", Marcos Antonio de Moraes retoma brevemente o histórico da recepção crítica da correspondência de Machado de Assis. Primeiramente, Moraes reafirma o consenso de que as cartas de Machado de Assis foram vistas pela crítica como material de pouco interesse literário (2011, p. 95-96).

Assim, Moraes menciona críticos como Agripino Griecco, Augusto Meyer e Lúcia Miguel Pereira que atribuíram pouca relevância às cartas de Machado de Assis. Posteriormente, Moraes cita críticas da década de 1980 de Alexandre Eulálio e Marília Rothier Cardoso, que apesar de concederem maior atenção à correspondência, dão continuidade a uma espécie de desvalorização desses textos. A desqualificação das cartas ocorre porque ambos comparam o estilo da ficção machadiana e o estilo epistolográfico do autor, com prejuízo para a avaliação do último (MORAES, 2011, p. 96-98).

Moraes cita, em adição, as críticas Maria Helena Werneck e Maria Cristina Cardoso Ribas que propuseram abordagens diferentes das cartas machadianas, mas apenas na década de 2000 (2011, p. 98-99). A iniciativa de publicação do conjunto da correspondência por critério cronológico ocorreria também apenas em 2008.

O histórico do estabelecimento da coleção das cartas pode ser acompanhado na apresentação do primeiro tomo da Correspondência de Machado de Assis, coordenada por Sérgio Paulo Rouanet e organizada por Irene Moutinho e Sílvia Eleutério. A partir da apresentação de Rouanet, inclusive, podemos questionar a contradição decorrente do fato de que pessoas e instituições preocuparam-se com a preservação dessas cartas, 
como Afrânio Peixoto e a ABL, enquanto grande parte da recepção crítica machadiana invalidou o estilo de escrita desses textos.

Assim, dado o cenário irregular da recepção crítica das cartas de Machado de Assis, Marcos Antonio de Moraes defende uma investigação da correspondência que vá além dos códigos de etiqueta epistolar do século 19 e que considere o estilo particular delas (2011, p. 100).

Moraes observa, em especial, que atualmente é possível abordar as cartas de Machado de Assis como textos que fazem parte dos "arquivos da literatura" (2011, p. 101). Ou seja, trata-se da leitura da correspondência que tem em vista a busca de "testemunhos" do processo de criação literária. Essa noção não existia no contexto brasileiro do século 19 e Moraes propõe justamente esse tipo de análise das cartas machadianas:

Um levantamento prévio de cartas de Machado de Assis que trazem à tona aspectos de sua produção literária abre a perspectiva de compreensão da natureza desses testemunhos. Trata-se, efetivamente, de aquilatar a abrangência e a profundidade reflexiva dos relatos, bem como a singularidade das formulações enunciativas epistolares, no que se refere ao memorialismo literário do escritor. Preliminarmente, três vertentes de análise das cartas revelam-se profícuas, conforme elas fixam: depoimentos do autor sobre projetos e processos de criação; aspectos da história da circulação das obras; e avaliações pessoais relativas à repercussão dos livros, tanto no espaço sigiloso da troca epistolar, quanto na imprensa. (MORAES, 2011, p. 101-102)

Na carta de 15 de agosto de 1865 a Castilho José, não se constata o testemunho de Machado de Assis sobre projetos, processos de criação e repercussão de livros que fossem propriamente seus. No entanto, nota-se o testemunho do autor enquanto crítico literário. Assim, propõe-se aqui a análise da carta, tendo em vista a repercussão dos juízos críticos de Machado de Assis em relação ao seu próprio projeto estético.

Comecemos, portanto, pelo fato de a carta ser aberta. Em função de se tratar de um texto de periódico, publicado no Diário do Rio de Janeiro, a carta de Machado de Assis encena o estabelecimento de uma rede de sociabilidade entre escritores numa determinada cena literária. Trata-se do circuito falante de língua portuguesa, decorrente do processo colonialista de Portugal, que possuía um estatuto peculiar ${ }^{1}$. 0 enunciador dialoga, assim, a partir do ponto de vista de uma antiga colônia.

Numa visada ainda mais específica, a rede estabelecida pela carta aberta de Machado de Assis constitui igualmente uma rede de referências literárias com a qual o autor deseja estabelecer diálogo, considerando seu crivo crítico e seu projeto estético.

As cartas de Machado de Assis articulam-se de maneira conforme a um jogo social. 0 escritor nele se insere, ao seguir suas regras. Nesse sentido, Marília Rothier Cardoso, apesar de insistir na comparação entre a qualidade de textos literários e epistolográficos, com prejuízo dos últimos, tem razão ao desvelar em Machado de Assis "o bom comportamento de suas cartas - perfeitamente integradas à farsa do jogo social de que participavam" (1985, p. 61).

No caso, a afirmação de Rothier Cardoso refere-se especialmente a cartas de Machado de Assis trocadas com Magalhães de Azeredo, entre 1889 e 1908. No entanto, a observação de um "bom comportamento" imperativo pode ser deslocado também para a correspondência de décadas anteriores. Na década 1860, o molde das regras sociais é visível, tanto em cartas formais, quanto em cartas familiares. No entanto, ao longo da correspondência machadiana, é notável que o estilo do autor mude em função do interlocutor e do assunto.

${ }^{1}$ Fernando Arenas aborda as peculiaridades da colonização e do pós-colonialismo em países de língua portuguesa No caso do Brasil, as relações coloniais foram excepcionais, pois mesmo antes da independência, o país tinha desenvolvido economia e produção mais expressivas que Portugal da independência, o país tinha desenvolvido economia e produção mais expressivas que Portugal (2005, p. 3). Em adição, Arenas retoma os argumentos de Boaventura Santos sobre a especificidade da colonização portuguesa. De forma muito resumida, trata-se de uma perspectiva que considera que depender do contexto e do ponto vista geopolítico em questão (2005, p. 3-5). 
Nesse sentido, o que podemos apreender da carta a José Feliciano de Castilho é a admiração de Machado de Assis em relação ao escritor, assim como em relação a José Mendes Leal e a outros autores citados, como Antonio Feliciano de Castilho e Almeida Garrett (ASSIS, 2008, p. 116). Ao fazer a crítica da peça por meio da carta, Machado fortalecia vínculos dentro de um sistema literário que pouco se articulava coletivamente e que dependia em grande parte de associações pessoais, inclusive, para o estabelecimento de contatos estrangeiros.

Contudo, para além das relações pessoais, é visível também na carta de Machado de Assis, a preocupação em demonstrar seu juízo crítico e em estabelecer referências intertextuais, ligando-se de forma literária. Assim, com a crítica dos Primeiros amores, Machado demonstra o desejo de retomada de determinada tradição de língua portuguesa, constituída por autores que se alinharam ao romantismo português, como Bocage (em parte), Garrett e os irmãos Castilho.

$\mathrm{Na}$ abertura da carta são perceptíveis tanto as intenções do plano das relações pessoais, quanto as intenções do plano das filiações literárias. Enquanto carta impressa em folhetim, ela possui um título: “Carta ao Senhor Conselheiro José Feliciano de Castilho". O vocativo muito respeitoso é "Mestre e senhor" e assim prossegue:

Conversemos de um grande poeta e de uma excelente obra, de Bocage e dos Primeiros amores de Bocage. Tem Vossa Excelência, mais do que nenhum outro, o direito de ver o seu nome nos altos destas linhas; foi Vossa Excelência, o primeiro que, depois de acurado estudo e prodigiosa investigação, nos deu uma excelente biografia do grande poeta, que serviu de fonte para outros trabalhos, e a que não duvidou recorrer o ilustre autor dos Primeiros amores. Tecer alguns aplausos a Vossa Excelência no meio dos aplausos ao autor da comédia, honrar a um tempo o biógrafo e o poeta, o historiador e o intérprete, é um dever de justiça literária, de que eu não me podia esquecer nesse momento.

Acresce ainda que, por uma coincidência auspiciosa para as letras, na época em que o Senhor Mende Leal traçava a sua comédia, Vossa Excelência entrava em novas investigações acerca da vida de Bocage, e, à mesma hora, desenhava-se no pensamento do erudito e no pensamento do poeta a grande figura do autor da Pena de Talião.

É a Vossa Excelência, portanto, que eu devo dar conta das minhas reflexões acerca dos Primeiros amores de Bocage. (ASSIS, 2008, p. 111-112)

O tom da carta é, portanto, solene. Além do vocativo inicial, o pronome de tratamento empregado para Castilho José é "Vossa Excelência”. Machado de Assis refere-se à crítica da peça como "dever de justiça literária". Outra imagem do campo semântico da justiça empregada por Machado é um epíteto de Bocage: "o autor da Pena de Talião" (2008, p. 111-112).

Retoricamente, a abertura da carta assemelha-se à técnica de captatio benevolentiae. Ou seja, Machado de Assis procura empregar os recursos necessários para demonstrar a importância do interlocutor e, assim, angariar sua afeição. Nesse sentido, para Machado, é necessário demonstrar que ambos, Castilho e Mendes Leal, são grandes homens de letras.

Dessa forma, na carta, Machado coloca-se numa posição retoricamente humilde. As imagens de justiça, por sua vez, constituem uma forma igualmente retórica de imparcialidade. Ou seja, posicionado como observador de um círculo de grandes letristas, a começar por Bocage, seguido por Mendes Leal e Castilho José, Machado ocuparia o lugar de um crítico que deve fazer juz à qualidade dos autores.

Ou seja, Machado não se apresenta na carta, de forma direta ou simplificada, como um escritor que propõe fazer a crítica de uma comédia sobre Bocage. Ele antes arma metáforas e utiliza técnicas retóricas para se apresentar como um escritor servo do "dever da justiça literária", que visa a atestar a qualidade das obras mencionadas (qualidade, no fundo, já reconhecida por todos) (2008, p. 112). Portanto, observamos que também na correspondência, o autor é passível de se constituir como um "eu" ficcionalizado por meio do estilo de escrita. 
Aliás, Machado estrategicamente lembra a circunstância de que Castilho José revisava a biografia sobre Bocage, no mesmo período. Dessa maneira, além de ter divulgado previamente o livro do amigo literário, Machado foi citado na revisão do biógrafo português.

Assim, José Feliciano de Castilho mencionaria Machado de Assis no livro publicado em 1867 no Rio de Janeiro pela Garnier, Manuel Maria du Bocage - Excerptos: seguidos de uma notícia sobre sua vida e obra. Castilho tece apreciações sobre a peça de José Mendes Leal justamente num dos capítulos dedicados à juventude de Bocage. Entre suas impressões, Castilho insere uma nota de rodapé sobre a crítica de Machado de Assis:

Numa carta sobre o drama do Sr. Mendes Leal, e sua representação no Rio de Janeiro, nos dirigio o esperançoso escritor fluminense Machado de Assis, se lê acerca d'este ponto do drama o seguinte bem pretenso e elegante paragrapho: [...]. (CASTILHO, 1867, p. 35)

Algumas marcas de assimetria entre os textos e os autores são perceptíveis. Enquanto Machado de Assis analisa a peça de Mendes Leal detalhadamente, Castilho aborda-a de maneira sintética. Castilho refere-se a Mendes Leal por meio de uma forma de tratamento igualitária, chamando-o de "nosso bom amigo" (1867, p. 34). A diferença de tratamento decorre tanto dos sujeitos envolvidos, quanto das possibilidades oferecidas por um gênero textual e pelo outro, no caso, a carta aberta e a biografia. Outro indício de assimetria é que a referência a Machado de Assis é discreta, feita numa nota de rodapé, com marca da nacionalidade e da juventude do escritor.

Nesse sentido, podemos perguntar se o pronome inclusivo "nosso" da expressão "nosso bom amigo" seria utilizado por Castilho para se referir aos portugueses. Possivelmente sim, já que o biógrafo menciona que a peça de Mendes Leal enriquece a "scena portuguesa", além de citar o público propriamente nacional da obra:
Os primeiros amores de Bocage é o título do último drama do Sr. Mendes Leal, drama que hoje impresso, os Portuguezes de além e aquém mar conhecem e admirão; não discursaremos pois sobre um livro de cujo mérito já a critica litteraria publicou verdades. (CASTILHO, 1867, p. 34)

Ao retomar ensaios que abordam a herança portuguesa e relações coloniais na obra de Machado de Assis como, por exemplo, "Machado de Assis no Portugal do século XIX", de Raymond S. Sayers, e "A recepção de Machado de Assis em Portugal", de Pedro Calheiros, é de se esperar a presença de marcas textuais de assimetria. Elas são indicativas de uma assimetria maior que está presente nos trânsitos entre cultura brasileira e portuguesa, do século 19, e que se encontram intricadas num sistema pós-colonial complexo.

Pedro Calheiros, por exemplo, concentra-se, sobretudo, na recepção do autor brasileiro em Portugal no século 20 e conclui que "Machado de Assis é pouco familiar aos portugueses" (1993, p. 87). Contudo, Calheiros aponta a recepção positiva da obra de Machado, no século 19, por Pinheiro Chagas, Julio Cesar Machado e Antonio Feliciano de Castilho, entre outros (1993, p. 53-54).

Raymond Sayers, por sua vez, possui uma abordagem mais voltada ao século 19. No artigo citado acima, ele menciona a amizade dos irmãos Castilho Antonio e Castilho José com o escritor brasileiro (1983, p. 125). Sayers conclui que as obras de Machado de Assis circularam irregularmente em Portugal, onde a fama do escritor fluminense provavelmente se deveu a relações pessoais advindas de amizades literárias e do casamento. Dessa forma, o crítico observa que muitas vezes Machado de Assis é reconhecido em Portugal como autor crítico e poeta em função de textos que datam do mesmo período dessas relações. Seu reconhecimento como romancista e contista em Portugal foi menor e mais esporádico (SAYERS, 1983, p. 140).

Assim, na referência que José Feliciano de Castilho faz a Machado de Assis, apesar de serem perceptíveis marcas de assimetria, notamos 
também a presença da correspondência da amizade e do estabelecimento da sociabilidade literária. Na biografia, Castilho reafirma as opiniões de Machado de Assis sobre a peça de Mendes Leal. Em adição, o único crítico dos Primeiros amores de Bocage que ele cita nominalmente é Machado de Assis. Por fim, Machado é referido por Castilho como o "esperançoso escritor fluminense" (1867, p. 34), caracterização que, por um lado, evidencia o lapso geracional entre os dois, mas, por outro, concede um elogio.

Vejamos, portanto, a crítica realizada por Machado de Assis na carta. As primeiras questões abordadas por Machado voltam-se ao gênero da peça e ao problema de representar a figura de Bocage. Nesse sentido, o escritor pondera:

O assunto de Bocage não era fácil. É coisa reconhecida que os homens de pensamento são difíceis de transportar para o teatro, ao passo que aí se dão perfeitamente os homens de ação. Além disso, a própria figura de Bocage tem uma feição histórica com que a arte deveria lutar. Mas de todas estas dificuldades poderia triunfar uma inteligência esclarecida. Tudo estava no modo por que o autor encarasse o assunto. Se ele atendesse à lição clássica, marcando o limite que separa a arte a história; se, com a segunda vista da musa, soubesse tirar das entranhas do assunto e do tempo tão somente aquilo que é digno da arte, fazendo-se imaginoso e intérprete, a obra deve ser necessariamente boa e o assunto fecundo. Esse foi o caminho seguido pelo Senhor Mendes Leal, e eis aí por que, além de uma excelente comédia, deu-nos também uma lição profícua [...]. (ASSIS, 2008, p. 113)

Esse é um ponto importante para compreender os desdobramentos da crítica literária de Machado de Assis na década de 1860 e em momentos posteriores. Ao aludir ao caso específico da feição histórica de Bocage, Machado apresentava a dificuldade de figurar o poeta. Contudo, Machado reconhece a chave do problema no procedimento de atender à lição clássica, que marca o limite entre arte e história. Ou seja, o autor defende a noção de verossimilhança enquanto concepção estética.
A "lição clássica" pode ser encontrada na Poética, de Aristóteles, no capítulo IX. Segundo a Poética aristotélica, a diferença entre poesia e história está no fato de que a primeira narra o que poderia acontecer, enquanto a segunda narra o que aconteceu. Ou seja, a poesia narra o universal, enquanto a história narra o particular. Por essa razão, Aristóteles argumenta que a poesia é superior à história, por ser mais filosófica e mais circunspecta, dado que a primeira tem como assunto o verossímil, e não o verdadeiro (1999, p. 47).

Ao longo da crítica de Machado de Assis, entre 1858 e 1879, observamos uma defesa recorrente da noção de verossimilhança e de decoro literário. Não se trata de afirmar que Machado de Assis tivesse seguido estritamente uma poética clássica, em especial, nas décadas de 1860 e de 1870. Trata-se antes de afirmar que, na concepção do projeto estético machadiano, a ideia da literatura como criação e composição era de grande relevância. Dessa forma, Machado elogia Mendes Leal porque o escritor português soube fazer-se "imaginoso e intérprete" (2008, p. 113). O modo machadiano de defesa do limite que "separa a arte da história", aliás, encontraria eco anos mais tarde na batalha "antirrealista" do autor, conforme veremos adiante.

Em seguida, na carta, Machado continua a comentar o problema do gênero da peça. Nesse ponto, surge outra noção defendida pelo autor, a saber, a prática dos caracteres:

Escrevendo os Primeiros amores de Bocage, o autor, segundo declara, quis abranger em uma só obra os três gêneros da comédia, a de caracteres, a de costumes, e a de enredo. Nenhuma é fácil, e a primeira é sobremodo difícil. Precisava empregar para esses três gêneros, três elementos principais: - a invenção lhe forneceria a trama, a erudição o iniciaria na pintura do tempo, a observação lhe daria a análise dos caracteres. [...]

Os caracteres, - é esse um dos principais méritos da obra, - estão desenhados com suma perfeição. (ASSIS, 2008, p. 113)

De fato, na "Introdução" dos Primeiros amores de Bocage, Mendes Leal primeiramente menciona o intuito de compendiar na peça os "três principais 
gêneros da comédia" (1865, p. I). 0 autor também argumenta que a comédia, propriamente, não tem lances violentos. Nesse sentido, ele se distancia do teatro francês e declara que deseja que "tudo sahisse de feição portuguesa" (LEAL, 1865, p. I). Em terceiro lugar, Mendes Leal justifica que não se propõe a fazer uma biografia, e sim uma comédia. Por esse motivo, o texto se concentra nos anos de juventude de Bocage, pintando a "aurora" de um homem "singular pela índole e pelo engenho" (1865, p. I).

Machado de Assis, portanto, comenta o compêndio dos três tipos de comédia que Mendes Leal declara fazer. Para o autor brasileiro, a comédia de enredo necessita de "invenção", a comédia de costumes de "erudição", e a comédia de caracteres de "observação". A primeira diz respeito à ação da peça. A segunda diz respeito à pintura de um contexto histórico, em que pesem regulações sociais significativas do período. Já a comédia de caracteres diz respeito ao desenho de personagens. Nela está implicada tanto a composição de tipos, quanto a composição de figuras humanas verossímeis.

Observamos que a crítica de Machado de Assis, apesar de comentar brevemente os três gêneros de comédia, detém-se, de forma especial, sobre a comédia de caracteres. Trata-se da modalidade favorita do autor brasileiro e a abordagem crítica preferencial dos caracteres não se desenrola sem consequências para sua própria obra.

A comédia de caracteres, nos Primeiros amores de Bocage, estruturase a partir da composição de personagens típicas, que são grotescas ou bem humoradas, da pintura de personagens históricas, como o Marquês de Marialva e o poeta satírico Tolentino, e, principalmente, do desenho central de Bocage. Já na "Introdução", Mendes Leal apresenta o problema de figurar Bocage, que decorre do tempo histórico transicional em que o poeta viveu (entre a passagem da vigência do classicismo para o romantismo) e da compreensão de sua vida como dividida em duas.
Na biografia de Castilho, na peça de Mendes Leal e na crítica de Machado de Assis, está presente uma tópica da duplicidade e da contradição na figura de Bocage. A forma como esses textos comentam o problema leva a entender que se trata de um motivo comum em torno do comentário da vida poeta. A divisão da figura de Bocage, em geral, dá-se entre o engenho de poeta, desde a representação dos anos de infância, e os desregramentos de sua vida, que ocorrem, em especial, na maturidade.

Na biografia de Castilho, por exemplo, encontramos um capítulo dedicado ao retrato físico de Bocage e quatro capítulos dedicados ao seu retrato moral. A descrição moral tem início pela "alma contradictoria" (1867, p. 170), que é composta por uma série de oxímoros. Por esse motivo, Castilho comenta que o poeta foi, comfrequência, difamado publicamente. Castilho pretende, então, examinar os traços de Bocage para compor uma descrição que fizesse jus ao poeta:

Não nos circunscrevamos porém a estas vagas reflexões, visto como a opinião prevenida injustamente estigmatisou um vulto que tem direito de ser encarado à sua verdadeira luz. [...]

Examinemos pois os fundamentos em que o julgamento de Bocage deva assentar. (CASTILHO, 1867, p. 170)

Assim, o caráter de Bocage desenhado por Castilho prossegue com várias qualidades morais, como: "religião"; "amor da pátria"; "liberdade"; "caridade, sensibilidade"; "melancolia"; "independência”; "inconstância” e "brutalidade" nos amores; "orgulho", entre outras (1867, p. 170-214).

Curiosamente, muitos dos dados da biografia são extraídos a partir de uma relação direta com a obra poética. Assim, um poema que demonstre sentimento religioso é integrado à argumentação da qualidade moral religiosa do poeta. Segundo o paradigma romântico, portanto, percebe-se uma espécie de identificação direta entre vida e obra. A diferença, contudo, que surge no gênero biográfico é a citação adicional de anedotas ou de fatos sobre a história do poeta, que pretendem certa veracidade. 
Considerando-se que Mendes Leal teve como referência a biografia de Castilho (LEAL, 1865, p. III), é perceptível o desenho do caráter da personagem, conforme os mesmos traços morais dos Excerptos. O Bocage de Mendes Leal é um poeta orgulhoso, que se dirige com arrogância aos poetas inferiores. É engenhoso em improvisações. Tem generosidade porque se apaixona por uma afilhada pobre e sacrifica-se por amor. Ao mesmo tempo, seu amor é inconstante. Além disso, ele preza pela liberdade e pelas amizades, entre outras características (LEAL, 1865).

Como já mencionado, também na peça de Mendes Leal faz-se presente o problema da difamação pública do poeta em contraposição às suas qualidades morais mais "autênticas". Na cena III, do ato II, Gonçalo, amigo de Bocage, aconselha-o a mudar de direção nas críticas, já que sua poesia satírica estava angariado inimigos, além de má fama, ao que o poeta responde:

\section{BOCAGE}

[...] Ouça-me também senhor, Gonçalo Mendo. Verá que avalio os seus affectuosos conselhos... E se alguma vez lhe disserem que Bocage é uma índole pertinaz e intractavel, poderá affirmar como a austeridade e a razao o acharam dócil. - Oiça-me. Não é novo para mim o que me diz. (LEAL, 1865, p. 76)

Dessa forma, a composição da personagem que Mendes Leal opera permanece fiel à representação romântica da vida de Bocage, segundo traços e qualidades morais que presidem seu retrato vigente. Por um lado, a peça de Mendes Leal dialoga com a biografia na construção do caráter de Bocage. Por outro, a peça é independente dos fatos biográficos, pois submete a ação ao interesse da maneira mais convincente de figurar o poeta, segundo determinada orientação estética.

Foi justamente esse tipo de procedimento dos Primeiros amores de Bocage que mais agradou Machado de Assis. Na produção crítica do autor, de 1858 a 1878, Machado mencionou com frequência a categoria dos caracteres enquanto aspecto relevante para a avaliação de crítica literária. Entre alguns dos textos que mais se destacam, nesse sentido, encontra-se, por exemplo, a crítica severa ao teatro de Joaquim Manoel Macedo, publicada em 1866. Nela, Machado faz asserções como as seguintes:

A novidade é só aquela que repugna à lógica dos caracteres. [...]

Em geral os caracteres destas duas peças são carregados e exagerados a tal ponto, que deixam longe de si o padrão humano. [...]

[...] ao ler as peças do sr. dr. Macedo dá vontade de perguntar se ele não tem em conta alguma as leis da arte, e os modelos conhecidos, se observa com atenção a natureza e seus caracteres, finalmente, se não está disposto a ser positivamente um artista e um poeta. [...]

[...] Nesta, como no Luxo e vaidade, vê-se um certo modo de pintar as personagens que lhe tira todas as condições humanas. (ASSIS, 2008, p. 1148-1151)

Na crítica que Machado faz da peça de Mendes Leal, a composição dos caracteres é também uma categoria literária central. Assim, na carta, Machado comenta que, na biografia de Castilho, Bocage tinha saído de Lisboa em função de ameaças políticas, enquanto, na peça, de forma contrária, Bocage sai de Lisboa para a Índia por um sacrifício feito em nome de sua amada (ASSIS, 2008, p. 114-115). Machado aplaude essa mudança realizada por Mendes Leal, pois julga que a peça deve articular-se a partir do caráter de Bocage (no sentido de categoria literária), e não a partir de dados factuais.

Portanto, é com grande relevância que Machado analisa a forma pela qual José Mendes Leal decide compor a figura do poeta:

0 autor dos Primeiros amores de Bocage tinha duas razões poderosas para pintar o Bocage que nos deu; [...] 0 autor tão consciencioso e tão verdadeiro, compreendeu bem que as linhas símpleces e características devem dominar os traços acidentais; o fundo do caráter e da índole de Bocage não eram os desregramentos referidos pela biografia e pela tradição oral. Se o autor fizesse deles a feição característica e saliente do poeta, tanto na época dos primeiros amores, como na dos últimos, teria desconhecido a lei do teatro, e a sua obra ficaria condenada a uma morte próxima. Mas, o Senhor Mendes Leal sabe perfeitamente a distância que há, entre os traços largos da pintura, e a implacável minuciosidade do daguerreotipo; não copiou a biografia, interpretou-a. (ASSIS, 2008, p. 114) 
Nota-se que Machado aborda um problema relativo aos caracteres e amplia-o para tangenciar uma questão de representação literária. Nesse sentido, retornamos ao argumento inicial de Machado de Assis, na crítica dos Primeiros amores. Ou seja, o argumento de que a arte deve figurar o universal, não o particular. Por isso, a pintura de Bocage deve ser interpretativa, imaginativa, criadora, e não uma suposta cópia da realidade.

Em termos gerais, esse tipo de posicionamento estético de Machado de Assis teve consequências em seu próprio projeto literário. Além do fato de que os caracteres foram recorrentes na produção crítica do autor, eles também o foram em sua produção ficcional. Dessa forma, por exemplo, no primeiro romance de Machado, Ressurreição, de 1872, o autor declarou ter o intuito de por em ação um pensamento de Shakespeare e o contraste de dois caracteres (2008, p. 236).

Em adição, nos demais romances de Machado de Assis, assim como em muitos contos, a figuração de tipos e a formação de personagens que se encontram envoltas em motivações morais e humanas constituem procedimentos cruciais.

Augusto Meyer, por exemplo, abordou Machado de Assis pelo viés da prosa de análise psicológica e moral (2008). Alfredo Bosi afirma que o comportamento humano é o principal objeto da ficção machadiana (2007, p. 11). Ivan Teixeira, por sua vez, analisou "O alienista", conforme o desenvolvimento do costume retórico dos caracteres na composição de uma galeria de personagens típicas (2010). Mais recentemente outros críticos investigaram a presença do psíquico na prosa de Machado de Assis (PASSOS C., 2009), bem como as personagens machadianas como "pessoas" (PASSOS J. L., 2014). Em todos esses casos da recepção crítica, há em comum a investigação do dado de figuração da dimensão humana nas personagens de Machado de Assis.

A célebre crítica de Machado de Assis a $O$ Primo Basílio, de 1878, aliás, é um texto que se ocupa da dimensão humana de personagens ou de sua “pessoa moral" (2008, p. 1233). Nesse artigo, o percurso de análise que o escritor realiza lembra em parte a argumentação sobre as qualidades da peça de José Mendes Leal.

Ou seja, na crítica a Eça de Queirós, mais uma vez, Machado de Assis parte de um problema relativo aos caracteres e expande o questionamento para um problema mais amplo que se refere ao campo da representação literária.

No artigo de 1878, Machado critica o processo de composição da personagem Luísa que, segundo o autor, é "um caráter negativo", "antes um títere do que uma pessoa moral” (2008, p. 1234). Em seguida, a discussão abre-se para a crítica do realismo de então (e mais especificamente, do naturalismo). Machado atacava, em especial, a proposta de descrição objetiva da realidade, em detrimento da figuração das paixões e das motivações humanas das personagens.

Assim, observa-se que da mesma forma como Machado criticou a "implacável minuciosidade do daguerreotipo" (2008, p. 114), na carta a José Feliciano de Castilho; anos depois, ele criticou "a reprodução fotográfica e servil das coisas mínima e ignóbeis”, na crítica a Eça de Queirós (2008, p. 1233).

Portanto, pode-se afirmar que a crítica a $O$ primo Basílio condensa várias concepções estéticas sobre as quais Machado de Assis debatia há décadas. A carta de 15 de agosto de 1865 a José Feliciano de Castilho é um dos indícios do tipo de crítica que Machado praticava.

Certamente a crítica de $O$ Primo Basílio ganhou mais destaque, entre outros textos do autor, por ter encenado uma competição literária, dentro do sistema cultural de língua portuguesa, com implicação da herança das relações coloniais. No debate de 1878 , houve não apenas um acirramento das questões decorrentes desse complexo cultural, mas também da rivalidade entre diferentes concepções de romance realista. 
Como já citado, a carta de 15 de agosto de 1865 a José Feliciano de Castilho também constituiu uma expressão da herança portuguesa e das relações coloniais na obra de Machado de Assis. Ela constitui igualmente um testemunho da crítica literária escrita por Machado de Assis, que reverbera em concepções estéticas presentes na obra ficcional do autor. Portanto, pode-se reafirmar a necessidade da leitura da correspondência machadiana enquanto “arquivo de literatura”. É necessário reafirmar também a relevância da leitura que se detenha sobre o estilo particular das cartas machadianas, considerando o contexto, interlocutor e tema de cada uma delas.

\section{Referências}

ARENAS, Fernando. [Dec. 1, 2009] (Post)colonialism, globalization, and lusofonia or the 'time-space', of the Portuguese-speaking world. Disponível em: <http://escholarship.org/ uc/item/0vh0f7t9>. Acesso em: 11 dez. 2014.

ARISTÓTELES. Poética. São Paulo: Nova Cultural, 1999.

ASSIS, Machado de. Obra completa, em quatro volumes. 2. ed. Rio de Janeiro: Nova Aguilar, 2008.

BOSI, Alfredo. Machado de Assis: o enigma do olhar. São Paulo: Ática, 2003.

CALHEIROS, Pedro. A recepção de Machado de Assis em Portugal. Travessia - Revista de Literatura do Curso de Pós-Graduação em Letras da Universidade Federal de Santa Catarina, Florianópolis, n. 27, p. 52-95, 1993.

CARDOSO, Marília Rothier. Jogo de cartas, uma leitura da correspondência de Machado de Assis. O eixo e a roda, Belo Horizonte, n. 4, p. 59-70, 1985.

CORRESPONDÊNCIA DE MACHADO DE ASSIS. Tomo I. Coordenação e orientação: Sergio Paulo Rounet; reunida, organizada e comentada por Irene Moutinho e Sílvia Eleutério. Rio de Janeiro: ABL, 2008.

EULÁLIO, Alexandre. Em torno de uma carta. In: CALIL, Carlos Augusto; BOAVENTURA, Maria Eugênia (Org.). Livro involuntário: literatura, história, matéria e memória. Rio de Janeiro: Editora UFRJ, 1993. p. 207-221.
LEAL, José Mendes da Silva. Os primeiros amores de Bocage. Lisboa: Tipografia Universal, 1865

MEYER, Augusto. Machado de Assis (1935-1958). 4. ed. Rio de Janeiro: José Olympio, ABL 2008

MORAES, Marco Antonio de. [2011]. Epistolografia de Machado de Assis: escrita de si e testemunhos de criação literária. Disponível em: <http://machadodeassis.net/revista/ numero07/rev_num07_artigo06.asp>. Acesso em: 11 dez. 2014.

NORONHA, José Feliano de Castilho Barreto e. Manuel Maria du Bocage - Excerptos: seguidos de uma notícia sobre sua vida e obra. Rio de Janeiro: B. L. Garnier, 1867. Tomo II PASSOS, Cleusa Rios Pinheiros. As armadilhas do saber. São Paulo: Editora da Universidade de São Paulo, 2009.

PASSOS, José Luiz. Romance com pessoas: a imaginação em Machado de Assis. Rio de Janeiro: Objetiva, 2014.

RIBAS, Maria Cristina Cardoso. [2008]. Onze anos de correspondência: os machados de Assis. Disponível em: <http://www.filologia.org.br/machado_de_assis/Onze\%20 anos $\% 20 \mathrm{de} \% 20$ correspond $\%$ C3\%AAncia $\% 20$ os $\% 20$ machados $\% 20 \mathrm{de} \% 20$ Assis.pdf $>$. Acesso em: 11 dez. 2014.

SAYERS, Raymond. Machado de Assis no Portugal do século XIX. In: Onze estudos de literatura brasileira. Rio de Janeiro: Civilização Brasileira, 1983, p. 123-142.

SCHWARZ, Roberto. Ao vencedor as batatas - forma literária e processo social nos inícios do romance brasileiro, 4. ed. São Paulo: Livraria Duas Cidades, 1992.

TEIXEIRA, Ivan. Machado de Assis e o costume retórico dos caracteres. Revista IEB, São Paulo, n. 51, p. 67-98, mar./set. 2010.

Recebido em 18 de dezembro de 2014.

Aceito em 10 de junho de 2015. 